\title{
Schisandrin B protects human keratinocyte-derived HaCaT cells from tert-butyl hydroperoxide-induced oxidative damage through activating the Nrf2 signaling pathway
}

\author{
MING DING ${ }^{1}$, PENG SHU ${ }^{2}$, SHUANG GAO ${ }^{3}$, FENGLOU WANG $^{4}$, YITIAN GAO $^{3}$, \\ YU CHEN ${ }^{3}$, WENJUAN DENG ${ }^{2}$, GAIYING HE ${ }^{4}$, ZHENLIN HU ${ }^{3}$ and TIANDUO $\mathrm{LI}^{1}$ \\ ${ }^{1}$ School of Chemistry and Pharmaceutical Engineering, Qilu University of Technology, Jinan, Shandong 250353; \\ ${ }^{2}$ Infinitus (China) Company, Ltd., Guangzhou, Guangdong 510663; ${ }^{3}$ Institute of Life Science, Wenzhou University, \\ Wenzhou, Zhejiang 325000; ${ }^{4}$ LB Cosmeceutical Technology Co., Ltd., Shanghai 200233, P.R. China
}

Received April 12,2018; Accepted September 6, 2018

DOI: $10.3892 / \mathrm{ijmm} .2018 .3901$

\begin{abstract}
Schisandrin B (Sch B), an active extract of Schisandra chinensis, has demonstrated antioxidant activity in a number of in vitro and in vivo models. In the present study, the capacity of Sch B to protect against oxidative injury in keratinocytes using the human keratinocyte-derived $\mathrm{HaCaT}$ cell line was investigated. To induce oxidative injury, tert-Butyl hydroperoxide (tBHP) was employed. The results indicate that Sch B efficiently reduced tBHP-induced cell death, reactive oxygen species (ROS) generation, protein oxidation, lipid peroxidation and DNA damage. Sch B also effectively attenuated the loss of mitochondrial membrane potential (MMP), and restored adenosine triphosphate (ATP) levels in tBHP-injured $\mathrm{HaCaT}$ cells. Furthermore, Sch B enhanced the expression of key antioxidant enzymes, including catalase, heme oxygenase-1, glutathione peroxidase, and superoxide dismutase, and further engaged the nuclear factor-erythroid 2-related factor 2 (Nrf2) signaling pathway by modulating its phosphorylation through activating multiple upstream kinases, including protein kinase $\mathrm{B}$, adenosine monophosphate-activated protein kinase and mitogen-activated protein kinases (MAPKs). The present study suggests that Sch B provides a protective effect in keratinocytes in response to oxidative injury via reinforcing the endogenous antioxidant defense system. Therefore, it may be applied as an adjuvant therapy or in health foods to delay the
\end{abstract}

Correspondence to: Professor Zhenlin $\mathrm{Hu}$, Institute of Life Science, Wenzhou University, 276 Xueyuan Road, Wenzhou, Zhejiang 325000, P.R. China

E-mail: zhenlinhu@hotmail.com

Professor Tianduo Li, School of Chemistry and Pharmaceutical Engineering, Qilu University of Technology, 3501 University Road, Jinan, Shandong 250353, P.R. China

E-mail: ylpt6296@vip.163.com

Key words: schisandrin B, keratinocytes, oxidative injury, nuclear factor-erythroid 2-related factor 2, anti-oxidative effect skin aging process and the onset of skin diseases caused by oxidative stress.

\section{Introduction}

Skin exposure to ultraviolet radiation and environmental toxic chemicals, such as air pollutants, heavy metals or ozone, can result in oxidative stress, which in turn accelerates the skin aging process and can directly cause disease (1). In addition, skin exposure to oxidizing chemicals present in cosmetic and pharmaceutical products can cause oxidative stress, leading to skin tissue and cellular damage. Oxidative stress is essentially the excess production of reactive oxygen species (ROS) beyond the control of the antioxidant defense system. ROS generation by cells under physiological conditions is important for the maintenance of cellular functional integrity. In a normal context, ROS are continuously generated through cellular respiration and other metabolic processes $(1,2)$. These highly reactive molecules have a wide range of physiological functions, acting as microbicidal agents and second messengers involved in cell proliferation and differentiation, and regulating numerous cellular signaling pathways (3). However, the overproduction of ROS can be induced in skin cells by exogenous irritants, such as ultraviolet radiation or chemical agents, causing direct oxidative damage to proteins, lipids and DNA (2). A variety of endogenous defense mechanisms exist in cells to constrain such damage, including the induction of the antioxidative proteins, glutathione peroxidase (GPx), catalase (CAT) and superoxide dismutase (SOD), which have enzymatic activity. Cells can further synthesize antioxidants that lack enzymatic activity, including glutathione (GSH), vitamins $\mathrm{C}$ and $\mathrm{E}$, and ubiquinol (4). These endogenous antioxidants protect cells from free radicals by reducing and neutralizing them. Normally there is balance between the antioxidant system and any ROS generation, but this balance is dynamic and tenuous. Any redox disturbances resulting in ROS overproduction or in faulty antioxidant mechanisms in skin cells may induce or aggravate skin diseases.

Tert-Butyl hydroperoxide (tBHP) is an organic peroxide that can be metabolized in cells by cytochrome P450 
to produce peroxyl and alkoxyl radicals or detoxified to tert-butanol, resulting in the rapid oxidation and depletion of cellular GSH. These pathways lead to oxidative injury of cells. Thus, tBHP is commonly employed as an exogenous oxidative stressor in cells and tissues in laboratory research (5-7). Previous work has shown that tBHP can cause oxidative damage to keratinocytes both in vitro and in vivo $(8,9)$. Thus, use of an exogenous inducer of oxidative stress, such as tBHP, may simulate situation of augmented oxidative stress in skin cells.

In mammalian cells, nuclear factor-erythroid 2-related factor 2 (Nrf2) regulates antioxidant protein expression and is itself a redox-sensitive transcription factor (10). In the absence of oxidative stress, Nrf2 remains in the cytoplasm and is constantly degraded via binding to Kelch-ECH-associated protein 1 (KEAP1), an adapter for the Cul3/Rbx1 E3 ubiquitin ligase that mediates Nrf2 ubiquitination and degradation. Keap1 is able to respond to changes in cellular redox conditions because it contains multiple reactive cysteine residues, the oxidation of which causes conformational changes that disrupt Nrf2 proteasomal degradation by altering the Keap1-Nrf2 complex. Other regulatory mechanisms, such as phosphorylation of particular residues within Nrf2, can also stabilize the protein, reducing its subsequent destruction (10). Kinases such as mitogen-activated protein kinases (MAPKs), phosphatidylionositol-3-kinase/Akt, protein kinase $\mathrm{C}$ and adenosine monophosphate-activated protein kinase (AMPK) have all been proposed as upstream kinases mediating Nrf2 phosphorylation (11). Nrf2 stabilization leads to its accumulation in the nucleus, allowing it to drive the transcription of target genes, including antioxidant genes, that contain the antioxidant response element (ARE). Extensive research has demonstrated that $\mathrm{Nrf} 2$ can be regulated by a range of pathways that modulate its binding to Keap1 and its subsequent stabilization. The appropriate regulation and cytoprotection cells may require the simultaneous activation of two or more such pathways, which together regulate $\mathrm{Nrf} 2$ activity in a cell type- and stimulant-dependent manner (12).

Given the importance of Nrf2 for cytoprotection from oxidative stress, and the deleterious contributions of ROS in the context of human physiology, developing compounds that modulate the Nrf2/Keap1/ARE pathway is of great research interest (13). It has been shown that many natural compounds with known antioxidant activity primarily elicit such activity by activating Nrf2 (11). Nrf2 itself has also been implicated in the regulation of mitochondrial homeostasis, proteasome activity, autophagy and stem cell renewal, all of which can in turn contribute to improved skin health and rejuvenation $(14,15)$. Thus, there is substantial opportunity for groups to develop naturally-derived compounds that can elicit Nrf2-mediated protection of the skin.

Schisandrin B (Sch B) is derived from the fruit of the traditional Chinese herb, Schisandra chinensis, which is traditionally used to treat hepatitis and cardiovascular disease (16). Studies have determined that Schisandra chinensis has numerous benefits, including the ability to protect against numerous stressors, including heat shock, burns, frostbite, swimming in a low oxygen environment, aseptic inflammation, irradiation and heavy metal toxicity (17). As one of the major active ingredients in Schisandra chinensis, Sch B has been extensively studied for its diverse pharmacological effects (18). Previous studies have demonstrated that Sch $\mathrm{B}$ has potent antioxidant and cytoprotective effects against different types of oxidative stress-induced cell injury in hepatocytes (19-21), cardiomyocytes $(22,23)$, neurcyte $(24,25)$, kidney tubule cells (26) and trophoblasts (27). In most of these cell types, the antioxidant effects of Sch B derive from Nrf2 activation and subsequent upregulation of antioxidant enzyme expression. Several in vivo studies have shown that Sch B treatment enhances antioxidant activity in liver, cardiac tissue, brain, and kidneys in various oxidative stress animal models (18,28-35). More recently, the antioxidant capacity of Sch B was tested in human skin cells, showing that Sch B could protect BJ human fibroblasts against solar irradiation-induced oxidative injury (36), and protect human keratinocytederived $\mathrm{HaCaT}$ cells against UVB-induced oxidative damage $(37,38)$. However, whether Sch B enhances antioxidant defenses in human skin cells via Nrf2 activation remains to be elucidated.

In the present study, activity of Sch B in tBHP-stimulated $\mathrm{HaCaT}$ cells was investigated, and the underlying mechanisms were explored. Primary areas of focus included its effects on apoptosis, intracellular ROS generation, mitochondrial dysfunction, oxidation biomarkers, antioxidant enzymes expression and the requirement for Nrf2 activation for cytoprotection against tBHP-induced oxidative damage.

\section{Materials and methods}

Materials. Sch B was obtained from Nature Standard Biotechnology Co., Ltd. (Shanghai, China). DMEM was purchased from Thermo Fisher Scientific, Inc. (Waltham, MA, USA). Fetal bovine serum (FBS) and penicillin/streptomycin were from Gibco (Thermo Fisher Scientific, Inc). Tert-Butyl hydroperoxide was purchased from Sigma-Aldrich (Merck KGaA, Darmstadt, Germany). Protein extraction kits for total protein were obtained from Beyotime Institute of Biochecnology (Jiangsu, China). The BCA kit was from Thermo Fisher Scientific, Inc.

Antibodies against Nrf2 (cat. no. ab62352), p-Nrf2 (cat. no. ab76026), Keap1 (cat. no. ab218815), JNK (cat. no. ab179461), p-JNK (cat. no. ab124956) and GAPDH (cat. no. ab181602) were purchased from Abcam (Cambridge, UK). Antibodies against p38 mitogen-activated protein kinase (p38 MAPK; cat. no. 8690), phospho-p38 MAPK (cat. no. 4511), Akt (cat. no. 4685), p-Akt (cat. no. 4060), Erk1/2 (cat. no. 4695), p-Erk1/2 (cat. no. 4370), AMPK (cat. no. 5832) and phospho-AMPK (cat. no. 2535) were purchased from Cell Signaling Technology, Inc. (Danvers, MA, USA), and anti-Lamin B (cat. no. sc-6217) was obtained from Santa Cruz Biotechnology, Inc. (Dallas, TX, USA). Goat anti-Mouse IgG H\&L (cat. no. ab216772) and Goat anti-Rabbit IgG H\&L (cat. no. ab216773) secondary antibodies were purchased from Abcam (Cambridge, UK).

Cell culture. HaCaT cells were purchased from Shanghai Zhong Qiao Xin Zhou Biotechnology Co., Ltd. (Shanghai, China; cat. no., ZQ0044) and cultured in DMEM containing $10 \% \mathrm{FBS}$ and penicillin/streptomycin. Cell culture took place at $37^{\circ} \mathrm{C}$ in $5 \% \mathrm{CO}_{2}$. Experiments were performed at $70 \%$ confluency. 
Cell viability assay. Cell Counting kit-8 (CCK-8; Dojindo Laboratories, Kumamoto, Japan) was used for viability assessment, according to the manufactuerer's protocol. Viability is expressed as \% of control optical density (OD).

Apoptosis assay. Annexin V, FITC Apoptosis Detection kit (Dojindo Laboratories, Kumamoto, Japan) was used to stain the cells, according to the manufactuerer's protocol. Fluorescence was quantified on a FACS Calibur flow cytomoeter (BD Biosciences, Franklin Lakes, NJ, USA). Numbers of Annexin V-FITC positive cells allowed for determination of apoptotic frequency.

Intracellular ROS measurement. Reactive Oxygen Species Assay kit (Beyotime Institute of Biotechnology) was employed to assess ROS production, according to the manufacturer's protocol. A flow cytometer was used to monitor production, and the results were analysed using CellQuest Pro software (version 5.2.1; BD Biosciences).

Mitochondrial membrane potential (MMP) assessment. MMP loss was evaluated by Mitochondrial membrane potential assay kit with JC-1 (Beyotime Institute of Biotechnology), according to the manufacturer's protocol. The cells were then assessed using a flow cytometer. The results were analyzed using CellQuest Pro software (version 5.2.1; BD Biosciences).

ATP level measurement. Intercellular ATP levels in HaCaT cells were measured via bioluminescence assay kit (Beyotime, Jiangsu, China) based on provided protocols. Levels of ATP were determined based on luciferase luminescence, after normalizing to total protein content.

Measurement of oxidation biomarkers. Malondialdehyde (MDA) content was assessed using Lipid Peroxidation MDA Assay kit (Beyotime Institute of Biotechnology), according to the manufacturer's instructions. The amount of 8-oxo-2'-deoxyguanosine (8-oxo-dG), a DNA damage marker, was determined with a Human 8-OhdG ELISA Kit (AMEKO, Shanghai, China), according to the manufacturer's instructions. Protein carbonyl levels were measured by Protein Carbonyl Colorimetric Assay Kit (Cayman Chemical, Ann Abor, MI, USA), according to the manufacturer's protocol.

Reverse transcription-quantitative polymerase chain reaction $(R T-q P C R)$. RNA was isolated from HaCaT cells following total RNA extraction using RNAfast 200 (Shanghai Fastagen Biotechnology Co., Ltd., Shanghai, China). Reverse transcription cDNA synthesis was performed using a High Capacity cDNA Reverse Transcription kit (Applied Biosystems, Foster City, CA, USA). Gene expression of various antioxidant enzymes was assessed with a SYBR-Green Master mix (Applied Biosystems). The specific primers are listed as follows: CAT forward, 5'-ATTCTGGAGAAGTGCGGAGA-3' and reverse, 5'-CGG CAATGTTCTCACACAGA-3'; HO-1 forward, 5'-CCAGGC AGAGAATGCTGAGT-3' and reverse, 5'-CTTGTTGCGCTC AATCTCCT-3'; SOD forward, 5'-AGGCTGTACCAGTGCAG GTC-3' and reverse, 5'-CAATAGACACATCGGCCACA-3'; GPX forward, 5'-CCAAGCTCATCACCTGGTCT-3' and reverse, 5'-TCGATGTCAATGGTCTGGAA-3'; and GAPDH forward,
5'-CAGGAGGCATTGCTGATGAT-3' and reverse, 5'-GAA GGCTGGGGCTCATTT-3'. The thermocycling conditions were as follows: Pre-denaturation at $95^{\circ} \mathrm{C}$ for $30 \mathrm{sec}$, amplification for 40 cycles by denaturing at $95^{\circ} \mathrm{C}$ for $5 \mathrm{sec}$, annealing at $60^{\circ} \mathrm{C}$ for $34 \mathrm{sec}$, followed by a final dissociation cycle of $95^{\circ} \mathrm{C}$ for $15 \mathrm{sec}, 60^{\circ} \mathrm{C}$ for $1 \mathrm{~min}$ and $95^{\circ} \mathrm{C}$ for $15 \mathrm{sec}$. GAPDH served as an internal normalization control. The relative expression of target genes were analyzed by $2^{-\Delta \Delta \mathrm{Ct}}$ method (39).

Western blotting. Total protein and nucleoprotein was extracted from HaCaT cells and quantified via BCA assay. A total of $40 \mu \mathrm{g}$ protein was loaded per lane and separated by $8 \%$ SDS-PAGE prior to transfer into $0.45-\mu \mathrm{m}$ nitrocellulose membranes. Membrane blocking was conducted for $1 \mathrm{~h}$ at room temperature with $5 \%$ non-fat dry milk. The membrane was probed at $4{ }^{\circ} \mathrm{C}$ overnight with primary antibodies against Nrf2 (dilution, 1:1,000), phospho-Nrf2 (dilution, 1:3,000), Keap1 (dilution, 1:500), JNK (dilution, 1:2,000), p-JNK (dilution, 1:2,000), GAPDH (dilution, 1:1,000), Akt (dilution, 1:1,000), phospho-Akt (dilution, 1:1,000), Erk1/2 (dilution, 1:1,000), p-Erk1/2 (dilution, 1:1,000), p38 MAPK (dilution, 1:1,000), phospho-p38 MAPK (dilution, 1:1,000), AMPK (dilution, 1:1,000), and p-AMPK. A secondary antibody incubation followed, using goat anti-mouse or goat anti-rabbit IgG H\&L secondary antibodies (dilution, 1:2,000) for $2 \mathrm{~h}$ at room temperature. An Odyssey CLx Infrared Imaging System (LI-COR, USA) was used to acquire and analyze the blots. GAPDH used as an internal control. The gray densities of the protein bands were quantified using ImageJ (version 1.4.3.67; National Institutes of Health, Bethesda, MD, USA).

Statistical analysis. GraphPad Prism (version 5.0; GraphPad Software, Inc., CA, USA) was used for all statistical analyses. One-way analysis of variance followed by Dunnett's test was used for comparison of means. $\mathrm{P}<0.05$ was considered to indicate a statistically significant difference.

\section{Results}

Sch B modulates tBHP-induced HaCaT cell death. In order to evaluate the protective effect of Sch B on tBHP-induced oxidative injury in $\mathrm{HaCaT}$ cells, we initially evaluated the cytotoxic effects of Sch B alone $(1,5,10,20,50$ and $100 \mu \mathrm{M})$ on HaCaT cells via CCK-8 assay. When HaCaT cells were treated with Sch $\mathrm{B}$ at $<20 \mu \mathrm{M}$ for $24 \mathrm{~h}$, cell viability did not decrease (Fig. 1A), indicating that Sch B exerted no cytotoxicity on $\mathrm{HaCaT}$ cells at $<20 \mu \mathrm{M}$.

To assess how $\mathrm{HaCaT}$ cells respond to oxidative stress, viability was measured in response to tBHP treatment. Viability decreased upon tBHP treatment (0.2-0.6 mM) for $6 \mathrm{~h}$ in a dose-dependent fashion (Fig. 1B). Furthermore, HaCaT-cell treatment with $0.4 \mathrm{mM}$ tBHP for 3-12 $\mathrm{h}$ further decreased viability in a time-dependent fashion (Fig. 1C). Since treatment with $0.4 \mathrm{mM}$ tBHP for $6 \mathrm{~h}$ resulted in $\sim 50 \%$ viability, this dose was selected for subsequent experiments regarding oxidative stress.

To determine how Sch B affects tBHP-induced cytotoxicity, $\mathrm{HaCaT}$ cells were treated with $10 \mu \mathrm{M}$ Sch B for $0,3,6,9$ and $12 \mathrm{~h}$, and sequentially incubated with $0.4 \mathrm{mM}$ tBHP for $6 \mathrm{~h}$. The CCK-8 assay demonstrated that pretreatment with Sch B for 

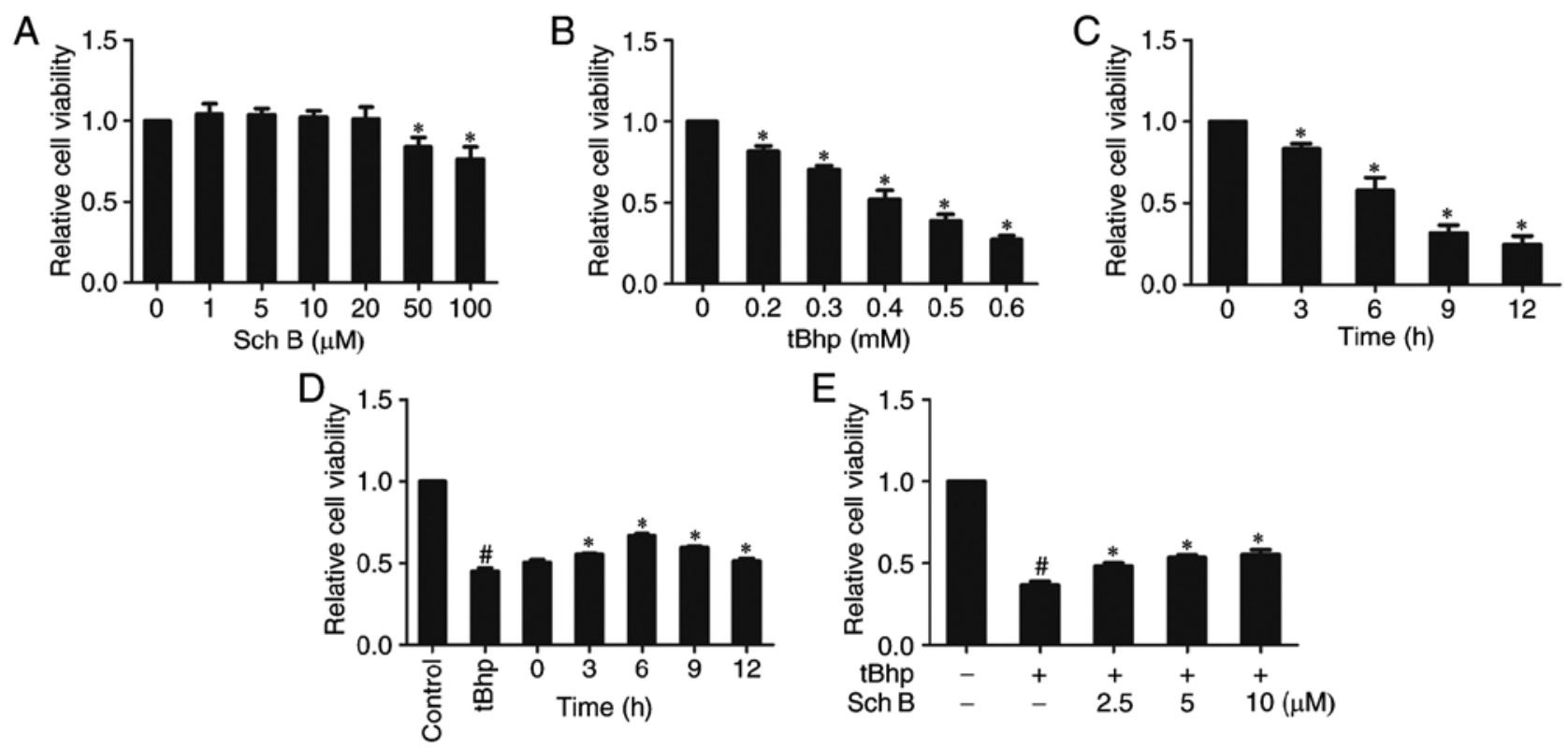

Figure 1. Sch B affects tBHP-induced toxicity. (A) Viability of HaCaT cells at the indicated concentrations of Sch B for 24 h; (B) Viability of HaCaT cells following treatment with the indicated concentrations of tBHP for $6 \mathrm{~h}$; (C) viability of HaCaT cells treated $0.4 \mathrm{mM}$ tBHP for the indicated periods of time; (D) viability of HaCaT cells treated with $10 \mu \mathrm{M} \mathrm{Sch} \mathrm{B}$ for the indicated periods of time, followed by treatment with $0.4 \mathrm{mM}$ tBHP for $6 \mathrm{~h}$; (E) viability of $\mathrm{HaCaT}$ cells treated with the indicated concentration of Sch B for $6 \mathrm{~h}$, followed by $0.4 \mathrm{mM}$ tBHP for $6 \mathrm{~h}$. Data are presented as the mean \pm standard error of the mean of three different experiments. ${ }^{~} \mathrm{P}<0.05$ vs. untreated control and ${ }^{*} \mathrm{P}<0.05$ vs. tBHP only control. Sch $\mathrm{B}$, Schisandrin $\mathrm{B}$; tBHP, tert-Butyl hydroperoxide.

$6 \mathrm{~h}$ provided the highest protective effect against tBHP-induced cytotoxicity in $\mathrm{HaCaT}$ cells (Fig. 1D). Therefore, a pretreatment time of $6 \mathrm{~h}$ was selected for use in subsequent experiments. $\mathrm{HaCaT}$ cells were treated with 2.5-10 $\mu \mathrm{M}$ Sch B for $6 \mathrm{~h}$ prior to $0.4 \mathrm{mM}$ tBHP treatment to induce oxidative stress. As shown in Fig. 1E, after $6 \mathrm{~h}$ treatment with tBHP alone, cell viability decreased by $>50 \%$ compared with no-treatment control, however, Sch B pretreatment mediated an increase in cell viability in tBHP-injured cells in a dose dependent fashion (Fig. 1E), suggesting that Sch B protected cells from tBHP-induced death. We further measured viability via Annexin V-FITC/PI staining. The time course of cell death induced by tBHP was examined, revealing that the number of apoptotic cells stained positive for Annexin V was markedly increased after $3 \mathrm{~h}$ of $0.4 \mathrm{mM}$ tBHP treatment, as compared with the untreated control. Increased tBHP exposure time (6-12 $\mathrm{h}$ ) led to an increased proportion of cells undergoing late apoptosis (Annexin-positive/PI-positive; Fig. 2A and B). To assess the protective effect of Sch B on tBHP-induced apoptosis, $\mathrm{HaCaT}$ cells were pretreated with Sch B for $6 \mathrm{~h}$ prior to induction of apoptosis with tBHP for $3 \mathrm{~h}$. The results demonstrated that Sch B pretreatment resulted in a dose-dependent decrease in apoptotic rate, indicating that Sch B has a marked protective effect against tBHP-induced apoptosis (Fig. 2C and D). Together, these experiments revealed that Sch B may prevent tBHP-induced $\mathrm{HaCaT}$ cell death.

Sch B affects intracellular ROS levels in $\mathrm{tBHP}$-injured HaCaT cells. To assess the role of oxidative stress in tBHP-induced injury in HaCaT cells, a DCFH-DA fluorescent probe was employed to measure intracellular ROS levels over time. The results demonstrated that tBHP treatment significantly increased the fluorescence intensity in $\mathrm{HaCaT}$ cells, indicating intracellular ROS generation. 2.5-10 $\mu \mathrm{M}$ Sch B inhibited ROS generation in a dose-dependent fashion (Fig. 3).
Sch $B$ affects $t B H P$-induced mitochondrial dysfunction in $\mathrm{HaCaT}$ cells. Oxidative stress can result in mitochondrial dysfunction, a major cause of apoptosis. To evaluate mitochondrial function, mitochondrial membrane potential (MMP) and intracellular ATP levels were measured. Both a loss of MMP expression and disruption in ATP energy supply are indicative of apoptosis. As predicted, tBHP reduced MMP expression, as indicated by the reduction in JC-1 fluorescence (Fig. 4A and B) and ATP production (Fig. 4C). Interestingly, Sch B treatment rescued the effect on MMP levels and ATP production in tBHP-injured HaCaT cells, indicating that Sch B can prevent mitochondrial dysfunction induced by tBHP in $\mathrm{HaCaT}$ cells (Fig. 4A-C).

Sch $B$ affects the tBHP-induced oxidation of biomolecules in $\mathrm{HaCaT}$ cells. Oxidative stress was further analyzed by evaluating oxidative damage to cellular biomolecules such as lipids, proteins and DNA. Sch B significantly reduced tBHP-induced MDA production in $\mathrm{HaCaT}$ cells, indicating a reduction in lipid peroxidation in response to this compound (Fig. 5A). Carbonylated protein levels were used to assess protein oxidation, and the results are presented in Fig. 5B: tBHP induced protein oxidation, whereas Sch B significantly inhibited this induction. Similarly, based on measurements of the damage marker 8-oxo-2'-deoxyguanosine (8-oxo-dG), Sch B also significantly attenuated tBHP-induced DNA damage (Fig. 5C). Thus, Sch B effectively attenuated tBHP-induced oxidative damage to biomolecules in $\mathrm{HaCaT}$ cells.

Sch $B$ affects the expression of antioxidant enzymes in tBHP-injured HaCaT cells. To determine whether Sch B protects $\mathrm{HaCaT}$ cells from tBHP-induced oxidative damage through inducing the expression of endogenous antioxidant enzymes, the effects of Sch B pretreatment on mRNA 


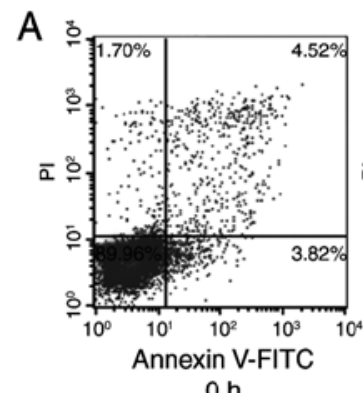

$\mathrm{Oh}$

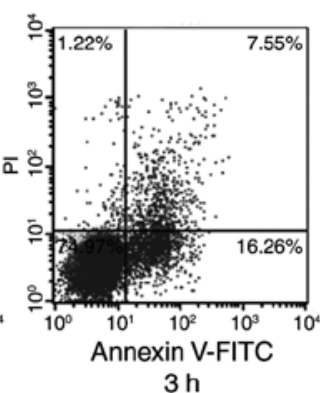

$3 \mathrm{~h}$

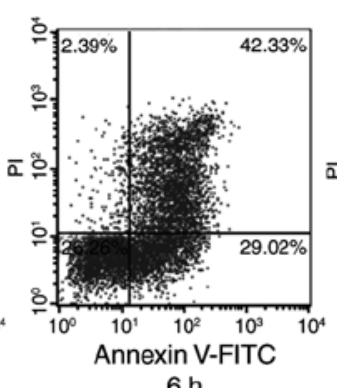

$6 \mathrm{~h}$

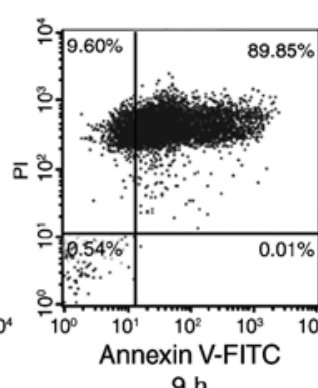

$9 \mathrm{~h}$

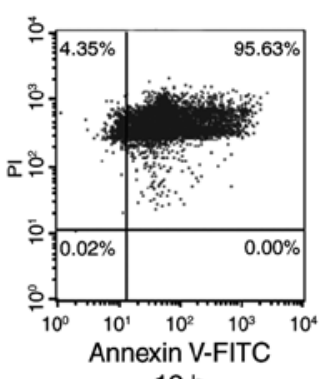

$12 \mathrm{~h}$
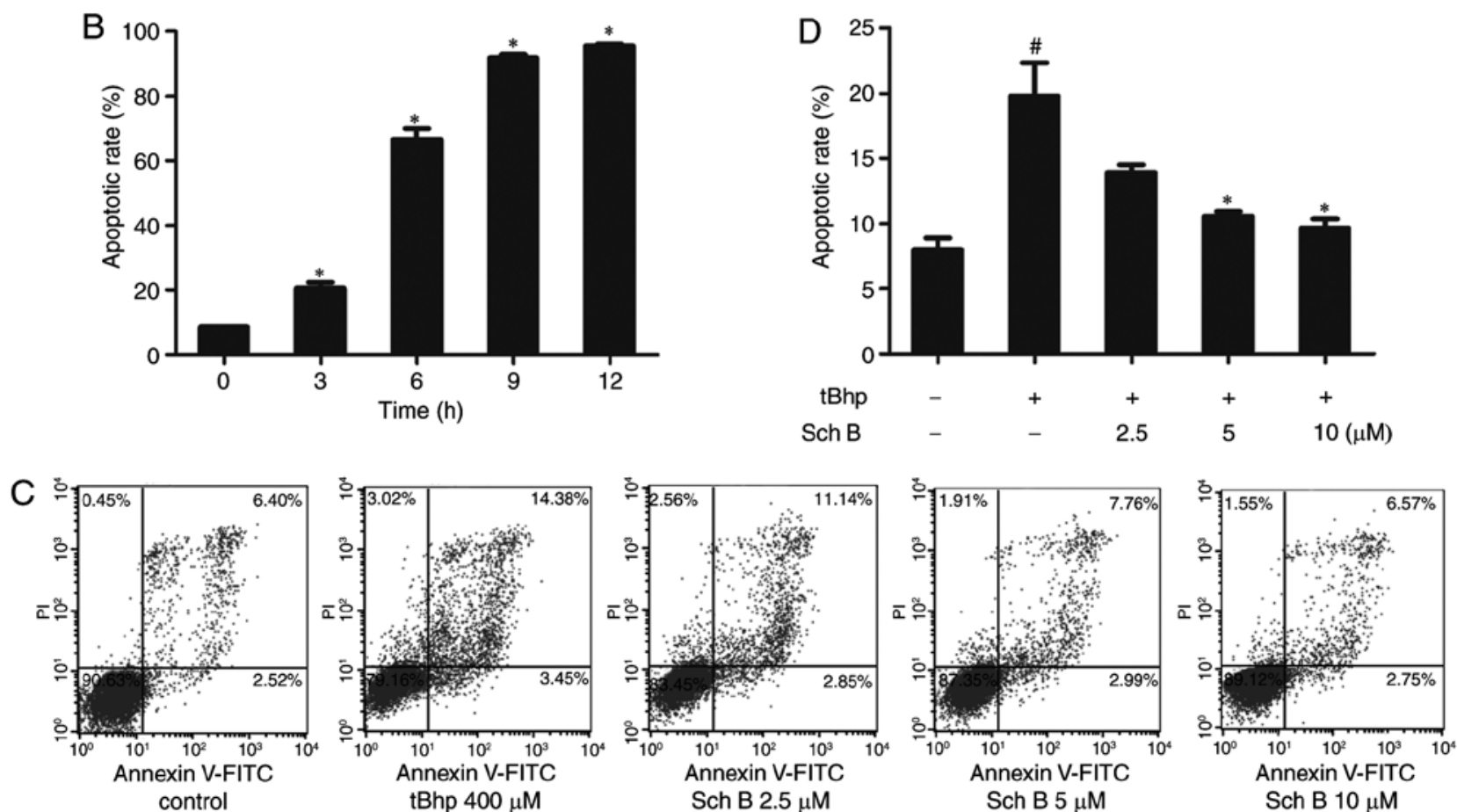

Figure 2. Sch B affects tBHP-induced apoptosis. (A) Flow cytometric analysis of HaCaT cells treated with 0.4 mM of tBHP for different periods of time, (B) quantification of the results presented as the mean \pm standard error of the mean of three different experiments. (C) Flow cytometric analysis of HaCaT cells pre-treated with the indicated concentrations of Sch B for $6 \mathrm{~h}$, then with $0.4 \mathrm{mM}$ tBHP for $3 \mathrm{~h}$. Annexin V/PI staining was then used to quantify apoptosis. (D) Apoptotic rate presented as the mean \pm standard error of the mean of three different experiments. ${ }^{\#} \mathrm{P}<0.05$ vs. untreated control and ${ }^{*} \mathrm{P}<0.05$ vs. tBHP only control. Sch B, Schisandrin B; tBHP, tert-Butyl hydroperoxide; PI, propridium iodide.

expression levels of antioxidant enzymes, including HO-1, SOD, GPx and CAT, were examined in tBHP-injured HaCaT cells. Our Figs. 1 and 2 indicate the rapid induction of cellular death by tBHP in $\mathrm{HaCaT}$ cells, and that exposure of $\mathrm{HaCaT}$ cells to $4 \mathrm{mM}$ tBHP for $3 \mathrm{~h}$ was enough to induce a significant increase in apoptotic rate. In order to demonstrate that the induction of antioxidant enzymes is responsible for the protective effects of Sch B, its effects on the expression levels of antioxidant enzymes after exposure to tBHP for $2 \mathrm{~h}$ were analyzed. As shown in Fig. 6, exposure to tBHP for $2 \mathrm{~h}$ did not significantly alter HO-1, SOD or GPx expression in $\mathrm{HaCaT}$ cells, but led to a significant decline in that of CAT. Notably, Sch B treatment prior to tBHP exposure significantly increased expression of HO-1, SOD and GPx, and restored tBHP-decreased CAT mRNA levels in HaCaT cells. These results suggest that Sch B can fortify the antioxidant system via increasing the expression of various antioxidant enzymes.

The effects of Sch B on Nrf2 activation. Asthe Nrf2/Keap1/ARE pathway is considered a master regulatory pathway of the induction of antioxidant enzymes under oxidative stress, we examined whether Sch B exerted anti-oxidant activity by activating the Nrf2 signaling pathway. tBHP alone resulted in a slight decrease in both nuclear and total Nrf2 protein levels compared with untreated cells, while Sch B treatment prior to tBHP stimulation further increased nuclear and total Nrf2 protein levels relative to the tBHP-only group in a dose-dependent fashion (Fig. 7A and B). This indicates that Sch B treatment resulted in Nrf2 accumulation and nuclear translocation. Sch B treatment did not alter Keap1 expression levels, but did markedly increased the phosphorylation level of Nrf2 (Fig. 7), suggesting that Sch B may activate Nrf2 via modulating its phosphorylation rather than acting on negative regulators. As AMPK, Akt and MAPKs (including Erk1/2, JNK and p38) have been proposed to function as upstream kinases that mediate the phosphorylation and activation of Nrf2, it was next examined how Sch B affects AMPK, Akt, and MAPK signaling, in order to investigate their role in the modulatory effect of Sch B on Nrf2. It was demonstrated that Sch B pretreatment followed by tBHP stimulation led to increased phosphorylation levels of AMPK, Akt, Erk1/2, 

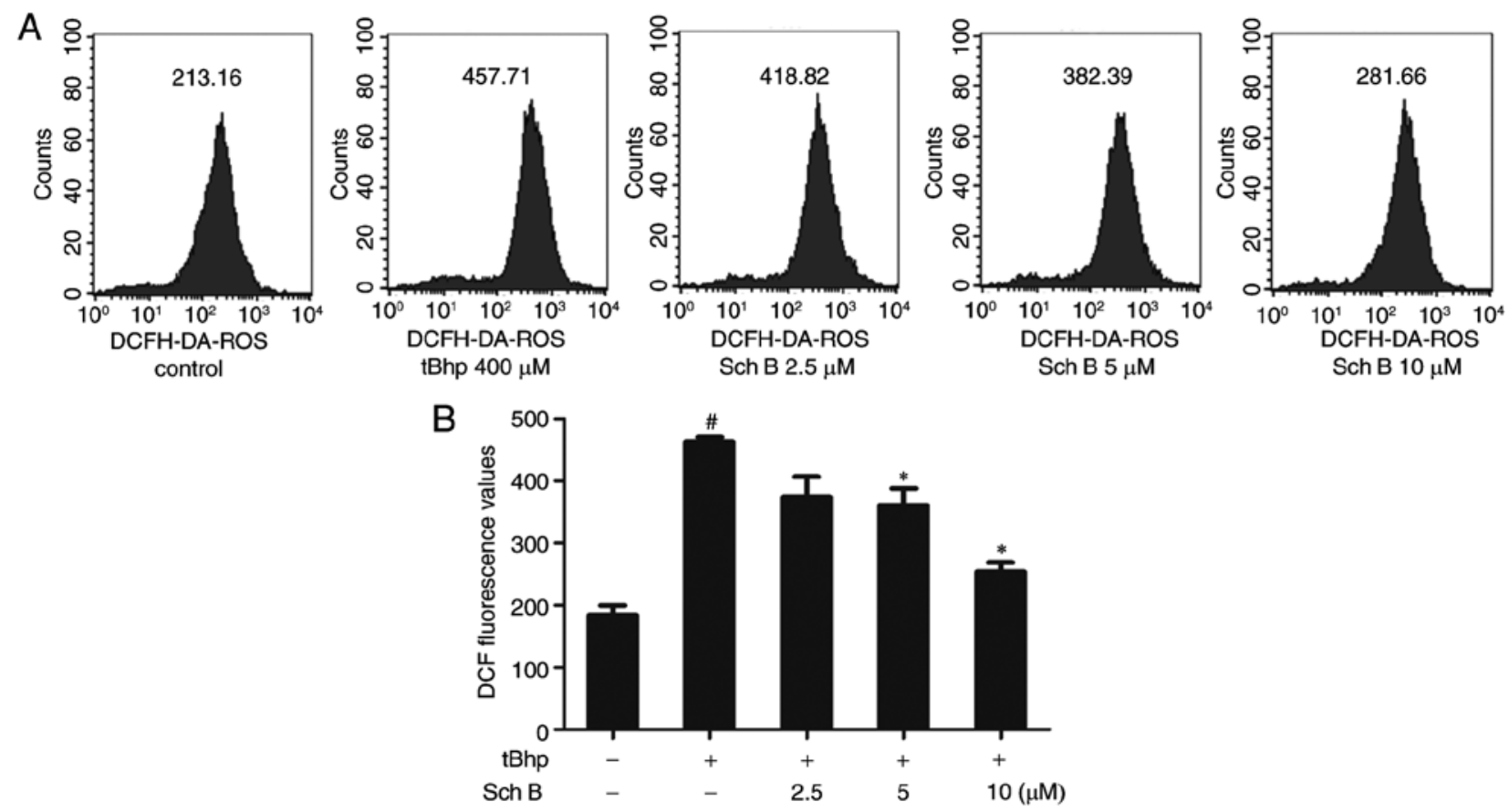

Figure 3. Sch B affects tBHP-induced ROS generation. HaCaT cells were treated with the indicated concentrations of Sch B for 6 h, then with 0.4 mM tBHP for $6 \mathrm{~h}$. (A) A DCFH-DA assay was then used to quantify intracellular ROS levels. (B) Fluorescence intensity presented as the mean \pm standard error of the mean of three different experiments. ${ }^{\#} \mathrm{P}<0.05$ vs. untreated control and ${ }^{*} \mathrm{P}<0.05$ vs. tBHP only control. Sch $\mathrm{B}$, Schisandrin $\mathrm{B}$; tBHP, tert-Butyl hydroperoxide; ROS, reactive oxygen species.
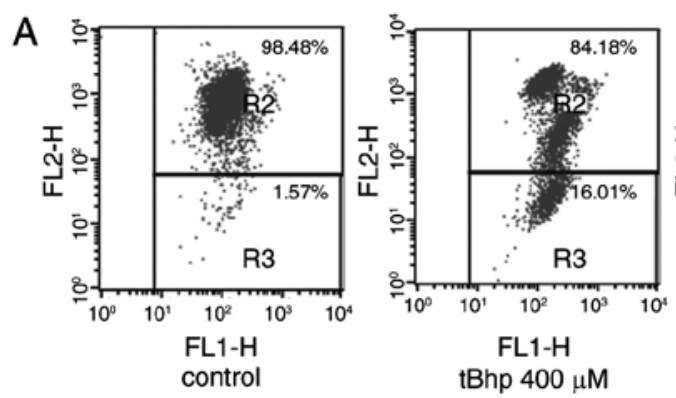

B

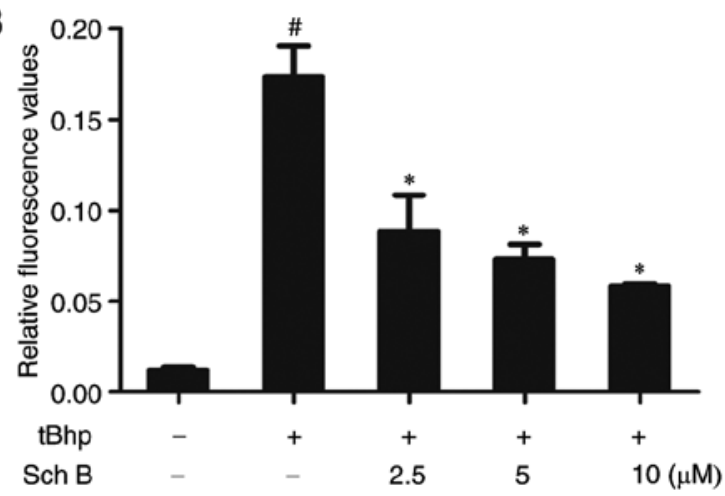

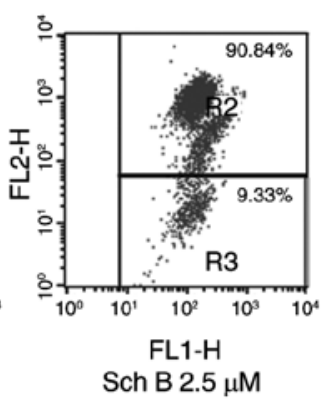
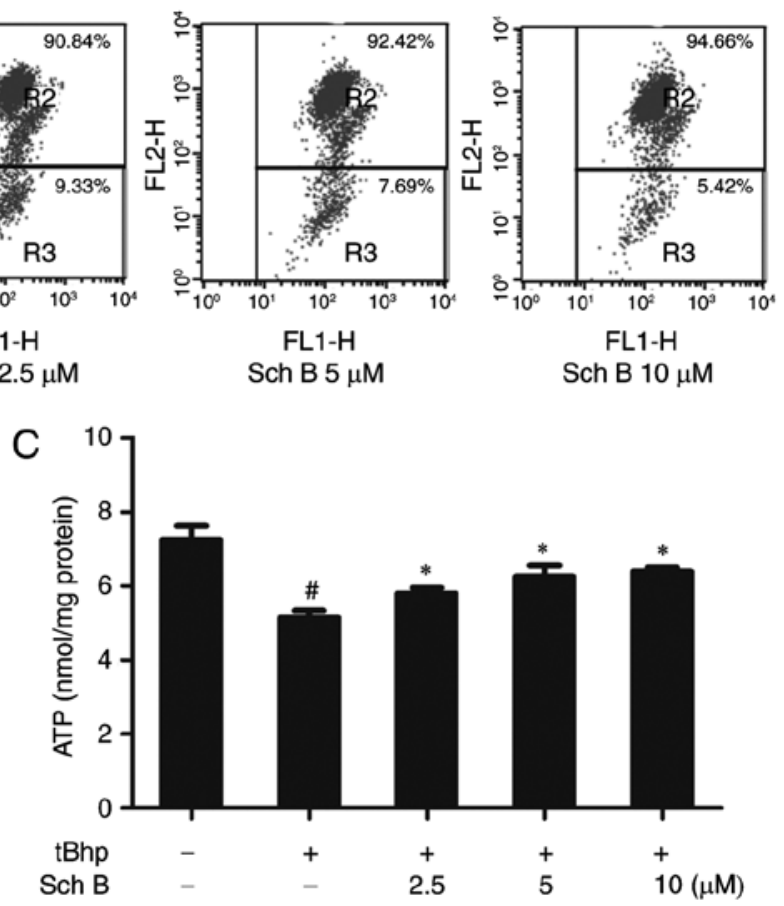

Figure 4. Sch B attenuates tBHP-induced mitochondrial dysfunction. HaCaT cells were pre-treated with the indicated amount of Sch B for 6 h, then treated with $0.4 \mathrm{mM}$ of tBHP for $6 \mathrm{~h}$. (A) JC-1 staining was used to assess the loss of MMP; (B) Fluorescence intensity presented as the mean \pm standard error of the mean of three different experiments. (C) The intracellular ATP level was measured via a bioluminescence assay, and the mean \pm standard error of the mean of three different experiments is shown. ${ }^{\#} \mathrm{P}<0.05$ vs. untreated control and ${ }^{*} \mathrm{P}<0.05$ vs. tBHP only control. Sch $\mathrm{B}$, Schisandrin $\mathrm{B}$; tBHP, tert-Butyl hydroperoxide; MMP, mitochondrial membrane potential.

JNK and p38 relative to tBHP treatment only (Fig. 7B and C). This suggests that the modulatory effect of Sch B on Nrf2 is mediated by multiple upstream kinases, including AMPK, Akt and MAPKs.

\section{Discussion}

In the present study, the ability of Sch B to shield cells from oxidative damage induced by tBHP was investigated in 


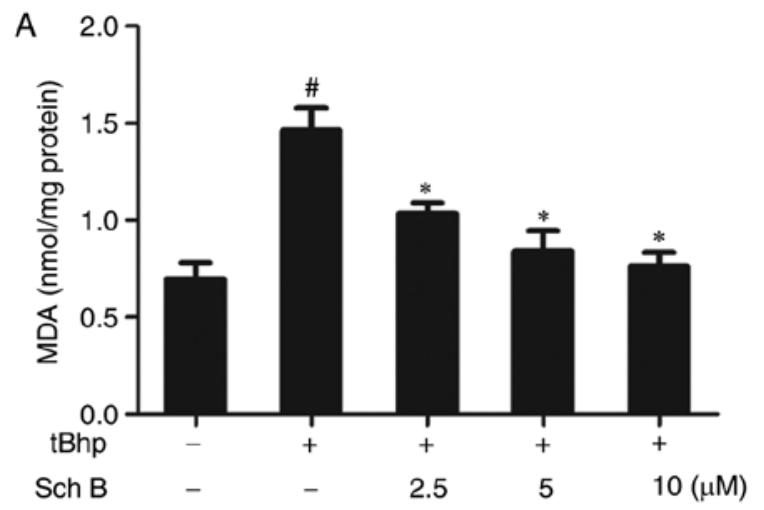

B
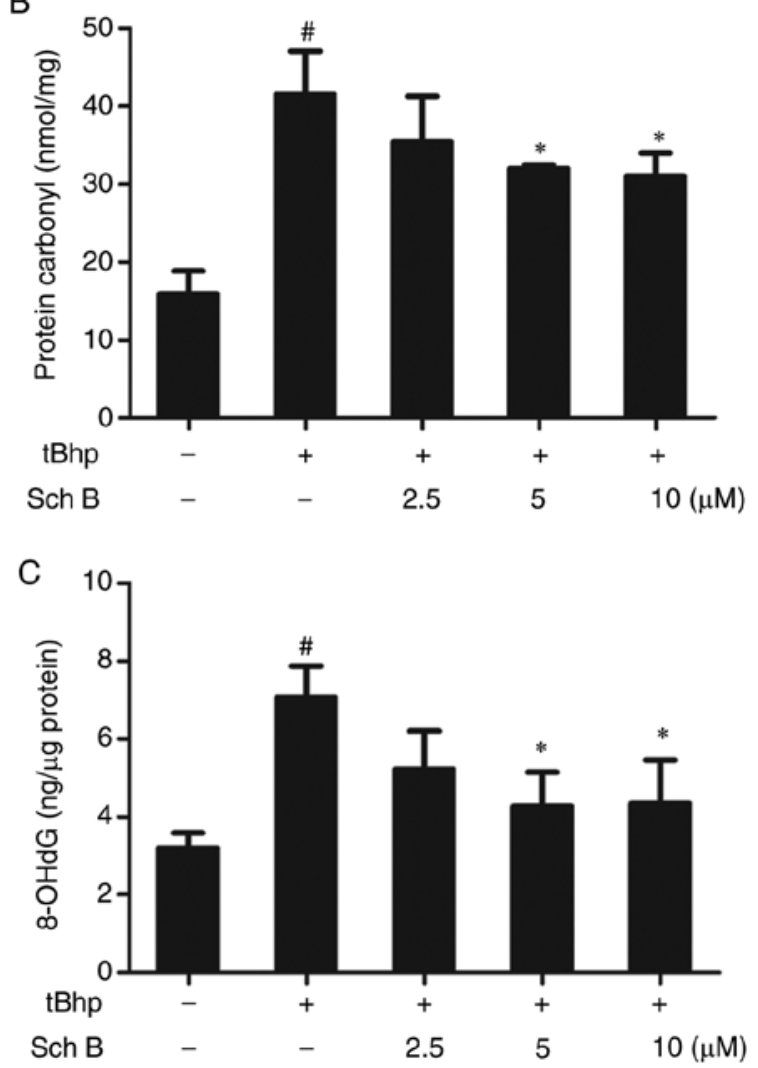

Figure 5. Sch B affects tBHP-induced oxidation of cellular biomolecules. $\mathrm{HaCaT}$ cells were pre-treated with the indicated concentration of Sch B for $6 \mathrm{~h}$, then treated with $0.4 \mathrm{mM}$ of tBHP for $6 \mathrm{~h}$. The levels of (A) MDA, (B) protein carbonyl, and (C) 8-oxo-dG were measured. Data are presented as the mean \pm standard error of the mean of three different experiments. ${ }^{\#} \mathrm{P}<0.05$ vs. untreated control and ${ }^{*} \mathrm{P}<0.05$ vs. tBHP only control. Sch $\mathrm{B}$, Schisandrin B; tBHP, tert-Butyl hydroperoxide; MDA, malondialdehyde; 8-oxo-dG, 8-oxo-2'-deoxyguanosine.

$\mathrm{HaCaT}$ cells. It was demonstrated that Sch B significantly decreased tBHP-induced cytotoxicity and apoptotic cell death. Furthermore, Sch B efficiently prevented tBHP-induced mitochondrial dysfunction and biomolecule oxidation in $\mathrm{HaCaT}$ cells. Notably, Sch B induced Nrf2 accumulation and promoted the transcription of its major target antioxidant enzymes, while inhibiting tBHP-induced ROS overproduction in HaCaT cells. These findings imply that $\mathrm{Sch} \mathrm{B}$ can protect $\mathrm{HaCaT}$ cells from tBHP-induced cell damage via enforcing its endogenous enzymatic antioxidant defense systems.

Mitochondria are major ROS producers within cells, and yet are themselves sensitive to oxidative stress. Redox impairment can easily cause mitochondrial dysfunction by inhibiting mitochondrially located enzymes associated with ATP production $(2,40)$. Disruption of oxidative phosphorylation directly affects respiratory chain electron flux, causing reduced MMP expression (41). This may be accompanied by increased electron leakage in the mitochondrial respiratory chain, enhancing ROS production. This can create a destructive feedback loop, which may drive activation of the intrinsic apoptotic pathway (42). Mitochondrial dysfunction, overproduction of ROS, and enhanced rates of cell death are important factors in aging and other human pathological processes $(43,44)$. In the present study, loss of the MMP, decreased mitochondrial ATP production, and overproduction of ROS were observed following tBHP challenge in $\mathrm{HaCaT}$ cells. These negative effects of tBHP on mitochondrial dysfunction were attenuated by Sch B pretreatment, which disrupted the tBHP-induced reduction in viability and apoptosis. These results indicate that Sch B may enhance or maintain mitochondrial function, thus allowing $\mathrm{HaCaT}$ cells to better resist tBHP-induced oxidative damage.

ROS can damage proteins, lipids, nucleic acids, and carbohydrates. In the context of weakening of antioxidant systems, oxidative damage may result in permanent changes in the redox state of these biomolecules, disrupting normal physiology. For example, lipid peroxidation in the cellular membrane can disrupt cell surface or mitochondrial membranes (45). Mitochondrial membrane damage in turn leads to cytochrome c release and intrinsic apoptosis (46). Numerous products derived from biomolecule oxidation are used as oxidation biomarkers to assess oxidative changes. The most widely used biomarkers include MDA for lipid peroxidation, carbonylated proteins for protein oxidation and $8-\mathrm{OHdG}$ for DNA oxidation $(47,48)$. It was found that the levels of MDA, carbonylated protein and $8-\mathrm{OHdG}$ were all substantially elevated in $\mathrm{HaCaT}$ cells exposed to tBHP, indicating a state of oxidative stress. Treatment of cells with Sch B reduced the levels of all oxidation biomarkers, confirming its ability to overcome tBHP-induced oxidative injury.

Antioxidant enzymes, including HO-1, SOD, GPx and CAT, are vital for the protection of cells against oxidative stressors. HO-1 is inducible and metabolizes heme to generate carbon monoxide (CO), biliverdin, and iron in a rate-limiting fashion. These heme derivatives possess antioxidant effects (49). SOD, GPx and CAT are responsible for the inactivation and elimination of superoxide and hydrogen peroxide (50). Therefore, these antioxidant enzymes are essential cytoprotective agents, defending cells from the toxic effects of ROS by maintaining relatively low intracellular ROS levels. In the present study, it was demonstrated that Sch B treatment increased antioxidant enzyme expression in tBHP-damaged $\mathrm{HaCaT}$ cells, indicating that the induction of endogenous antioxidant enzymes mediates the protective effects of Sch B, at least in part.

$\mathrm{Nrf} 2$ is the key transcription factor regulating antioxidant enzyme expression. Its activity is primarily regulated via interaction with Keap1, which sequesters Nrf2 in the cytoplasm and directs it for degradation by the proteasome. Nrf2 phosphorylation also regulates the activity of Keapl by facilitating its translocation into the nucleus (51). In the present study, Sch $\mathrm{B}$ treatment resulted in an increase in total and nuclear Nrf2 in 

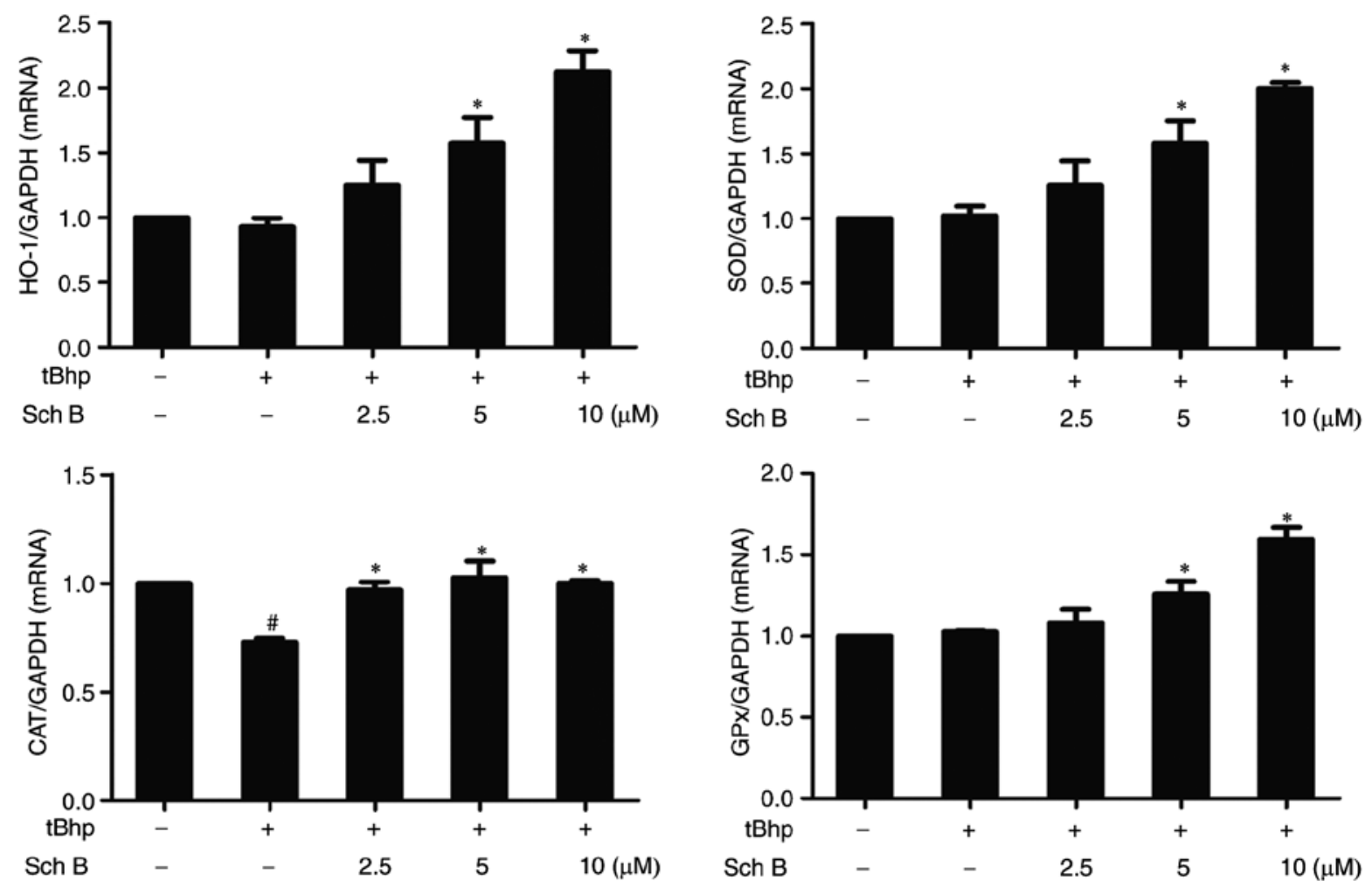

Figure 6. Sch B affects the expression of antioxidant enzymes in tBHP-injured cells. HaCaT cells were pre-treated with the indicated amount of Sch B s for $6 \mathrm{~h}$, then treated with $0.4 \mathrm{mM}$ of tBHP for $2 \mathrm{~h}$. HO-1, SOD, CAT, and GPx expression was then measured by reverse transcription-quantitative polymerase chain reaction. Data are presented as the mean \pm standard error of the mean of three different experiments ${ }^{\#} \mathrm{P}<0.05$ vs. untreated controls and ${ }^{*} \mathrm{P}<0.05$ vs. tBHP only control. Sch B, Schisandrin B; tBHP, tert-Butyl hydroperoxidesuperoxide dismutase; HO-1, heme oxygenase 1; SOD, superoxide dismutase; CAT, catalase; GPx, glutathione peroxidase.

tBHP-challenged HaCaT cells, indicating that the Nrf2 pathway was activated by Sch B, which is involved in the Sch B-mediated induction of antioxidant enzymes. Sch B also induced Nrf2 phosphorylation without altering levels of Keap1, suggesting that Sch B most likely activates Nrf2 via modulating its phosphorylation. A number of protein kinases, such as PI3K/Akt, MAPKs and AMPK, serve as upstream signals mediating Nrf2 phosphorylation under oxidative stress (52-54). Phosphorylation of these kinases was assessed as a readout for their activation, and it was demonstrated that Sch B treatment markedly induced the phosphorylation of multiple kinases, including 3 members of MAPKs (Erk1/2, JNK and p38), Akt and AMPK, suggesting that the activation of Akt, MAPKs and AMPK may contribute to Sch B-induced Nrf2 phosphorylation and its subsequent transcriptional activation. This is partially consistent with previous studies that determined that MAPK signaling upon Sch B treatment of hepatocyte and cardiomyocyte cell lines led to Nrf2 activation $(19,22)$. Together, these results suggest that Sch B may activate multiple upstream kinases by inducing their phosphorylation, and that they, in turn, phosphorylate Nrf2 and facilitate its nuclear translocation, leading to the expression of antioxidant enzymes.

In conclusion, the present study demonstrated that, in human keratinocyte-derived $\mathrm{HaCaT}$ cells, Sch B exhibited a protective ability against tBHP-induced cytotoxicity and apoptotic cell death by preventing mitochondrial dysfunction, suppressing intracellular ROS generation, and mitigating biomolecule oxidation. These findings further suggest that Sch B activates Nrf2 via phosphorylation of its upstream kinases, including Akt, MAPKs (Erk1/2, JNK and p38) and AMPK, leading to transcription of antioxidant enzymes, including HO-1, SOD, GPx, and CAT, which protect cells against oxidative stress. These results support the use of Sch B to protect skin against oxidative stress, and associated diseases and conditions including skin aging.

\section{Acknowledgements}

Not applicable.

\section{Funding}

The preset study was supported by the Opening Project of Zhejiang Provincial Top Key Discipline of Pharmaceutical Sciences (grant no. YKFJ3-010).

\section{Availability of data and materials}

All data generated or analyzed during this study are included in this published article.

\section{Authors' contributions}

$\mathrm{ZH}$ and MD conceived and designed the experiments. MD, FW, YC and YG performed the experiments. ZH, TL, PS and GH analyzed the data. $\mathrm{ZH}, \mathrm{SG}$, WD prepared the manuscript. $\mathrm{ZH}$ and MD revised the manuscript. All authors read and approved the final manuscript. 
A

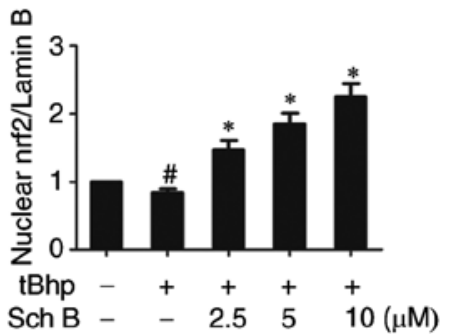

B
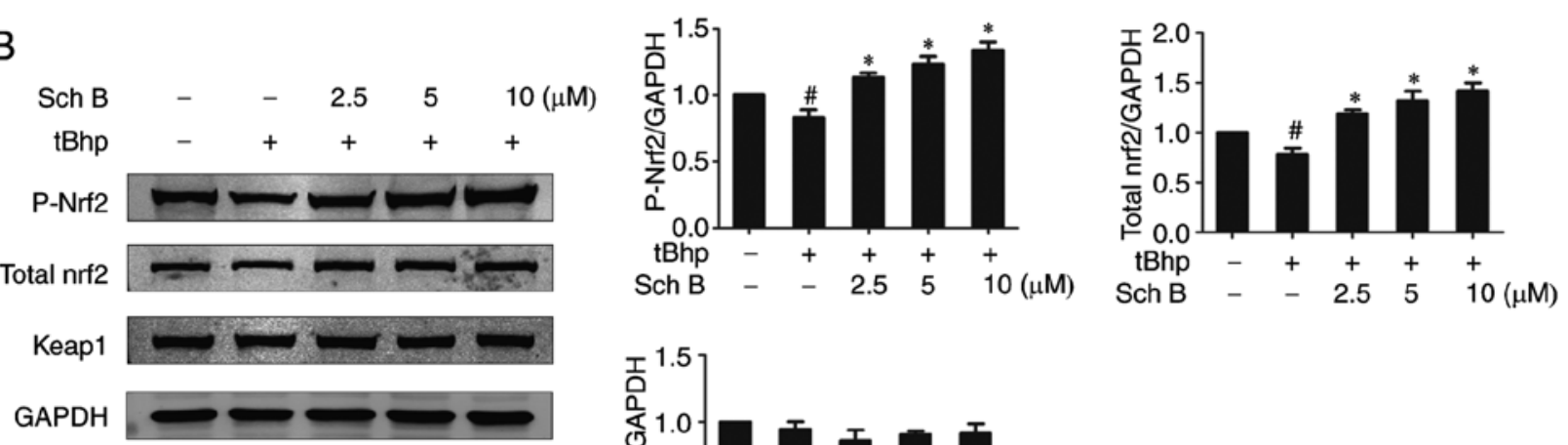

GAPDH
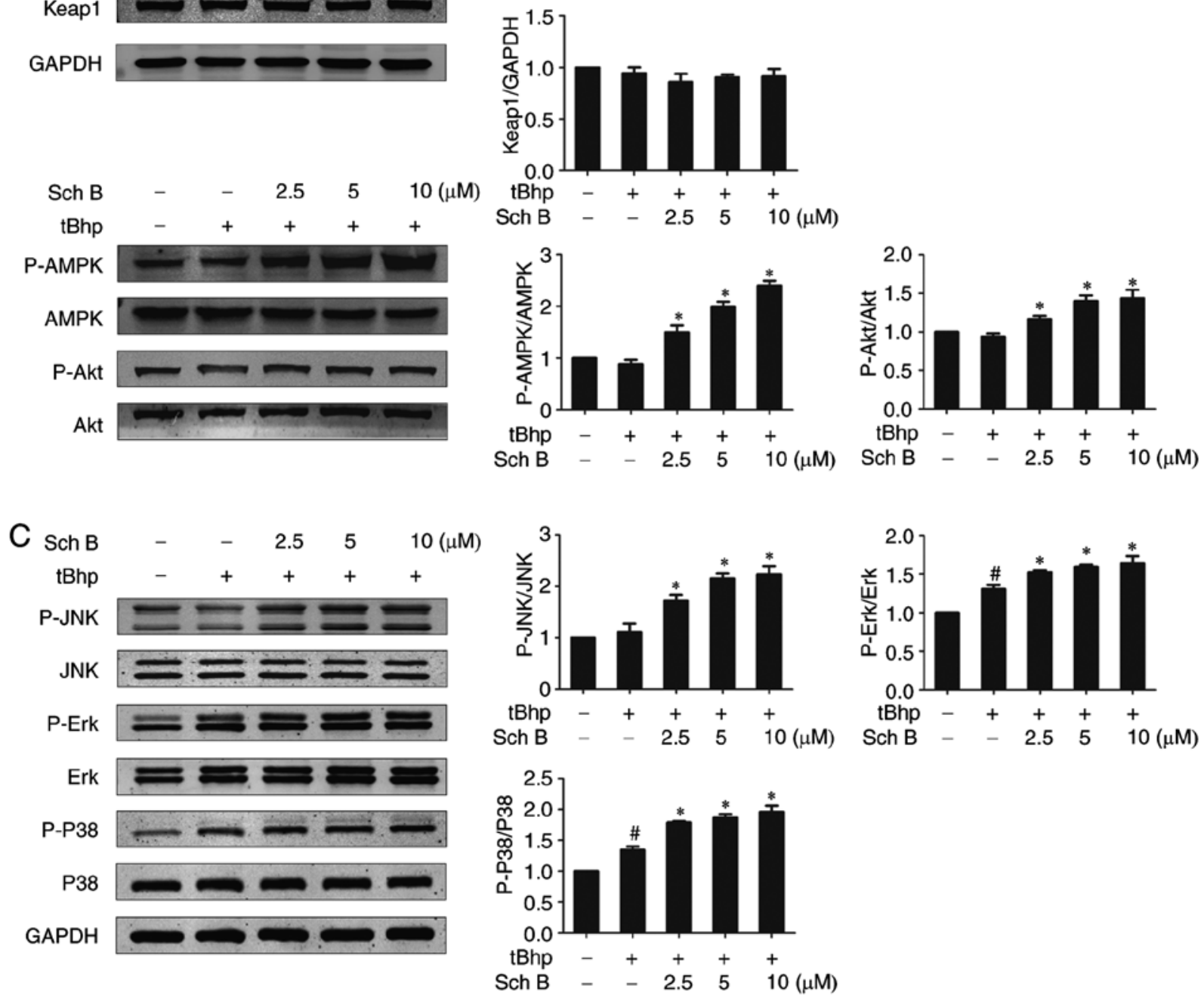

Figure 7. Sch B affects Nrf2 activation. HaCaT cells were pre-treated with the indicated amounts of Sch B for $6 \mathrm{~h}$, then treated with $0.4 \mathrm{mM}$ of tBHP for $1 \mathrm{~h}$. (A) Nuclear Nrf2 protein levels were assessed by western blotting and quantified by densitometric analysis of (n=3). (B) The levels of total Nrf2, Keap1, Akt, AMPK and as well as phosphorylated levels were assessed via western blotting, and quantified by densitometric analysis. (C) The levels of MAPKs (including JNK, Erk1/2 and p38) and their phosphorylated levels were assessed via western blotting and quantified by densitometric analysis $(n=3)$. Data are presented as the mean \pm standard error of the mean of three different experiments. "P $<0.05$ vs. untreated controls. "P< $<0.05$ vs. tBHP only control. Sch B, Schisandrin B; Nrf2, nuclear factor-erythroid 2-related factor 2; tBHP, tert-Butyl hydroperoxidesuperoxide dismutase; Keap1, Kelch-ECH associated protein 1; AMPK, monophosphate-activated protein kinase; MAPK, mitogen acctivatd protein kinase; Erk, extracellular signal-regulated kinase; p-, phosphorylated.

\section{Ethics approval and consent to participate}

Not applicable.

\section{Patient consent for publication}

Not applicable. 


\section{Competing interests}

The authors declare that they have no competing interests.

\section{References}

1. Kudryavtseva AV, Krasnov GS, Dmitriev AA, Alekseev BY, Kardymon OL, Sadritdinova AF, Fedorova MS, Pokrovsky AV, Melnikova NV, Kaprin AD, et al: Mitochondrial dysfunction and oxidative stress in aging and cancer. Oncotarget 7: 44879-44905, 2016.

2. Valko M, Leibfritz D, Moncol J, Cronin MT, Mazur M and Telser J: Free radicals and antioxidants in normal physiological functions and human disease. Int J Biochem Cell Biol 39: 44-84, 2007.

3. de Magalhães JP and Church GM: Cells discover fire: Employing reactive oxygen species in development and consequences for aging. Exp Gerontol 41: 1-10, 2006.

4. Shindo Y, Witt E, Han D, Epstein W and Packer L: Enzymic and non-enzymic antioxidants in epidermis and dermis of human skin. J Invest Dermatol 102: 122-124, 1994.

5. Crane D, Haussinger D, Graf P and Sies H: Decreased flux through pyruvate dehydrogenase by thiol oxidation during t-butyl hydroperoxide metabolism in perfused rat liver. Hoppe Seylers Z Physiol Chem 364: 977-987, 1983.

6. Bellomo G, Thor $\mathrm{H}$ and Orrenius S: Increase in cytosolic $\mathrm{Ca}^{+}$ concentration during t-butyl hydroperoxide metabolism by isolated hepatocytes involves NADPH oxidation and mobilization of intracellular Ca2 ${ }^{+}$stores. FEBS Lett 168: 38-42, 1984.

7. Kucera O, Endlicher R, Rousar T, Lotkova H, Garnol T, Drahota Z and Cervinkova Z: The effect of tert-butyl hydroperoxide-induced oxidative stress on lean and steatotic rat hepatocytes in vitro. Oxid Med Cell Longev 2014: 752506, 2014.

8. Vessey DA, Lee KH and Blacker KL: Characterization of the oxidative stress initiated in cultured human keratinocytes by treatment with peroxides. J Invest Dermatol 99: 859-863, 1992.

9. Wikramanayake TC, Simon J, Mauro LM, Perez CI, Roberts B, Elgart G, Alvarez-Connelly E, Schachner LA and Jimenez JJ: Tert-butyl hydroperoxide, an organic peroxide, causes temporary delay in hair growth in a neonatal rat model. Clin Exp Dermatol 36: 661-664, 2011.

10. Niture SK, Khatri R and Jaiswal AK: Regulation of Nrf2-an update. Free Radic Biol Med 66: 36-44, 2014.

11. Surh YJ, Kundu JK and Na HK: Nrf2 as a master redox switch in turning on the cellular signaling involved in the induction of cytoprotective genes by some chemopreventive phytochemicals. Planta Med 74: 1526-1539, 2008.

12. Hybertson BM and Gao B: Role of the Nrf2 signaling system in health and disease. Clin Genet 86: 447-452, 2014.

13. Bosch R, Philips N, Suárez-Pérez JA, Juarranz A, Devmurari A, Chalensouk-Khaosaat J and Gonzalez S: Mechanisms of photoaging and cutaneous photocarcinogenesis, and photoprotective strategies with phytochemicals. Antioxidants (Basel) 4: 248-268, 2015.

14. Holmström KM, Kostov RV and Dinkova-Kostova AT: The multifaceted role of Nrf2 in mitochondrial function. Curr Opin Toxicol 1: 80-91, 2016.

15. Hawkins KE, Joy S, Delhove JM, Kotiadis VN, Fernandez E, Fitzpatrick LM, Whiteford JR, King PJ, Bolanos JP, Duchen MR, et al: NRF2 orchestrates the metabolic shift during induced pluripotent stem cell reprogramming. Cell Rep 14: 1883-1891, 2016.

16. Liu GT: Pharmacological actions and clinical use of fructus schizandrae. Chin Med J (Engl) 102: 740-749, 1989.

17. Panossian A and Wikman G: Pharmacology of Schisandra chinensis Bail: An overview of Russian research and uses in medicine. J Ethnopharmacol 118: 183-212, 2008.

18. Lam PY and Ko KM: Schisandrin B as a hormetic agent for preventing age-related neurodegenerative diseases. Oxid Med Cell Longev 2012: 250825, 2012.

19. Leong PK, Chiu PY, Chen N, Leung H and Ko KM: Schisandrin B elicits a glutathione antioxidant response and protects against apoptosis via the redox-sensitive ERK/Nrf2 pathway in AML12 hepatocytes. Free Radic Res 45: 483-495, 2011.

20. Lam PY, Leong PK, Chen N and Ko KM: Schisandrin B enhances the glutathione redox cycling and protects agains oxidant injury in different types of cultured cells. Biofactors 37: 439-446, 2011
21. Chiu PY, Leung HY, Poon MK, Mak DH and Ko KM: Effects of schisandrin $\mathrm{B}$ enantiomers on cellular glutathione and menadione toxicity in AML12 hepatocytes. Pharmacology 77: 63-70, 2006.

22. Chiu PY, Chen N, Leong PK, Leung HY and Ko KM: Schisandrin $\mathrm{B}$ elicits a glutathione antioxidant response and protects against apoptosis via the redox-sensitive ERK/Nrf2 pathway in H9c2 cells. Mol Cell Biochem 350: 237-250, 2011.

23. Chiu PY and Ko KM: Schisandrin B-induced increase in cellular glutathione level and protection against oxidant injury are mediated by the enhancement of glutathione synthesis and regeneration in AML12 and H9c2 cells. Biofactors 26: 221-230, 2006.

24. Lam PY and Ko KM: (-)Schisandrin B ameliorates paraquat-induced oxidative stress by suppressing glutathione depletion and enhancing glutathione recovery in differentiated PC12 cells. Biofactors 37: 51-57, 2011

25. Ba Q, Cui C, Wen L, Feng S, Zhou J and Yang K: Schisandrin B shows neuroprotective effect in 6-OHDA-induced Parkinson's disease via inhibiting the negative modulation of miR-34a on Nrf2 pathway. Biomed Pharmacother 75: 165-172, 2015.

26. Lai Q, Luo Z, Wu C, Lai S, Wei H, Li T, Wang Q and Yu Y: Attenuation of cyclosporine A induced nephrotoxicity by schisandrin B through suppression of oxidative stress, apoptosis and autophagy. Int Immunopharmacol 52: 15-23, 2017.

27. Dong Q, Hou H, Wu J and Chen Y: The Nrf2-ARE pathway is associated with Schisandrin $b$ attenuating benzo(a)pyrene-Induced HTR cells damages in vitro. Environ Toxicol 31: 1439-1449, 2016.

28. Chen Q, Zhang H, Cao Y, Li Y, Sun S, Zhang J and Zhang G: Schisandrin B attenuates CCl4-induced liver fibrosis in rats by regulation of Nrf2-ARE and TGF- $\beta /$ Smad signaling pathways. Drug Des Devel Ther 11: 2179-2191, 2017.

29. Chiu PY, Leung HY, Poon MK and Ko KM: Chronic schisandrin B treatment improves mitochondrial antioxidant status and tissue heat shock protein production in various tissues of young adult and middle-aged rats. Biogerontology 7: 199-210, 2006.

30. Chiu PY, Tang MH, Mak DH, Poon MK and Ko KM: Hepatoprotective mechanism of schisandrin B: Role of mitochondrial glutathione antioxidant status and heat shock proteins. Free Radic Biol Med 35: 368-380, 2003

31. Thandavarayan RA, Giridharan VV, Arumugam S, Suzuki K, Ko KM, Krishnamurthy P, Watanabe $\mathrm{K}$ and Konishi T: Schisandrin B prevents doxorubicin induced cardiac dysfunction by modulation of DNA damage, oxidative stress and inflammation through inhibition of MAPK/p53 signaling. PLoS One 10: e0119214, 2015

32. Chen N, Chiu PY and Ko KM: Schisandrin B enhances cerebral mitochondrial antioxidant status and structural integrity, and protects against cerebral ischemia/reperfusion injury in rats. Biol Pharm Bull 31: 1387-1391, 2008.

33. Chiu PY, Leung HY and Ko KM: Schisandrin B enhances renal mitochondrial antioxidant status, functional and structural integrity, and protects against Gentamicin-Induced nephrotoxicity in rats. Biol Pharm Bull 31: 602-605, 2008.

34. Ko KM and Lam BY: Schisandrin B protects against tert-butylhydroperoxide induced cerebral toxicity by enhancing glutathione antioxidant status in mouse brain. Mol Cell Biochem 238: 181-186, 2002.

35. Ko KM, Chen N, Leung HY, Leong EP, Poon MK and Chiu PY: Long-term schisandrin B treatment mitigates age-related impairments in mitochondrial antioxidant status and functional ability in various tissues, and improves the survival of aging C $57 \mathrm{BL} / 6 \mathrm{~J}$ mice. Biofactors 34: 331-342, 2008.

36. Chiu PY, Lam PY, Yan CW and Ko KM: Schisandrin B protects against solar irradiation-induced oxidative injury in BJ human fibroblasts. Fitoterapia 82: 682-691, 2011.

37. Hou W, Gao W, Wang D, Liu Q, Zheng S and Wang Y: The protecting effect of deoxyschisandrin and schisandrin $\mathrm{B}$ on $\mathrm{HaCaT}$ cells against UVB-induced damage. PLoS One 10: e0127177, 2015.

38. Gao C, Chen H, Niu C, Hu J and Cao B: Protective effect of Schizandrin B against damage of UVB irradiated skin cells depend on inhibition of inflammatory pathways. Bioengineered 8: 36-44, 2017.

39. Livak KJ and Schmittgen TD: Analysis of relative gene expression data using real-time quantitative PCR and the 2(-delta delta C(T)) method. Methods 25: 402-408, 2001

40. Nulton-Persson AC and Szweda LI: Modulation of mitochondrial function by hydrogen peroxide. J Biol Chem 276: 23357-23361, 2001. 
41. Lieven CJ, Vrabec JP and Levin LA: The effects of oxidative stress on mitochondrial transmembrane potential in retinal ganglion cells. Antioxid Redox Signal 5: 641-646, 2003.

42. Wang $\mathrm{CH}, \mathrm{Wu} \mathrm{SB}, \mathrm{Wu}$ YT and Wei YH: Oxidative stress response elicited by mitochondrial dysfunction: Implication in the pathophysiology of aging. Exp Biol Med (Maywood) 238: 450-460, 2013.

43. Naidoo K, Hanna R and Birch-Machin MA: What is the role of mitochondrial dysfunction in skin photoaging? Exp Dermatol 27: 124-128, 2018.

44. Tulah AS and Birch-Machin MA: Stressed out mitochondria: The role of mitochondria in ageing and cancer focussing on strategies and opportunities in human skin. Mitochondrion 13: 444-453, 2013.

45. Girotti AW: Photosensitized oxidation of membrane lipids: Reaction pathways, cytotoxic effects, and cytoprotective mechanisms. J Photochem Photobiol B 63: 103-113, 2001.

46. Chipuk JE, Bouchier-Hayes L and Green DR: Mitochondrial outer membrane permeabilization during apoptosis: The innocent bystander scenario. Cell Death Differ 13: 1396-1402, 2006.

47. Hawkins CL, Morgan PE and Davies MJ: Quantification of protein modification by oxidants. Free Radic Biol Med 46: 965-988, 2009.

48. Marrot L and Meunier JR: Skin DNA photodamage and its biological consequences. J Am Acad Dermatol 58 (5 Suppl 2): S139-S148, 2008.
49. Motterlini R and Foresti R: Heme oxygenase-1 as a target for drug discovery. Antioxid Redox Signal 20: 1810-1826, 2014.

50. Goyal MM and Basak A: Hydroxyl radical generation theory: A possible explanation of unexplained actions of mammalian catalase. Int J Biochem Mol Biol 3: 282-289, 2012.

51. Bryan HK, Olayanju A, Goldring CE and Park BK: The Nrf2 cell defence pathway: Keap1-dependent and -independent mechanisms of regulation. Biochem Pharmacol 85: 705-717, 2013.

52. Chen HH, Chen YT, Huang YW, Tsai HJ and Kuo CC: 4-Ketopinoresinol, a novel naturally occurring ARE activator, induces the $\mathrm{Nrf} 2 / \mathrm{HO}-1$ axis and protects against oxidative stress-induced cell injury via activation of PI3K/AKT signaling. Free Radic Biol Med 52: 1054-1066, 2012.

53. Sun Z, Huang Z and Zhang DD: Phosphorylation of Nrf2 at multiple sites by MAP kinases has a limited contribution in modulating the Nrf2-dependent antioxidant response. PLoS One 4: e6588, 2009.

54. Shen G, Hebbar V, Nair S, Xu C, Li W, Lin W, Keum YS, Han J, Gallo MA and Kong AN: Regulation of Nrf2 transactivation domain activity. The differential effects of mitogen-activated protein kinase cascades and synergistic stimulatory effect of Raf and CREB-binding protein. J Biol Chem 279: 23052-23060, 2004. 